Niepełnosprawność. Dyskursy pedagogiki specjalnej

Nr 36/2019

Disability. Discourses of special education

No. 36/2019

\title{
Grzegorz Stunża
}

Uniwersytet Gdański

\section{Trendy techno-edukacyjne a potrzeba rozwijania kompetencji przyszłości. Wyzwania edukacji uczestnictwa}

Artykuł podejmuje temat aktualnych trendów technologicznych w edukacji. Wskazuje je, akcentując, że funkcjonują w kontekście przemian związanych z czwartą rewolucją technologiczną. Zwraca uwage, jak istotna dla pedagogiki, w tym pedagogiki specjalnej, jest refleksja nad skutkami korzystania z nowych technologii. Niezmiernie ważne jest także projektowanie zastosowań nowości oraz fakt, że nie da się myśleć o ich korzystaniu i przygotowywaniu do używania ich (oraz kolejnych technologii) bez namysłu pedagogicznego. Rozpatrując nowości przez pryzmat umiejętności, wiedzy, ale równie mocno przekazywanych wartości. W tym celu autor sięga do pojęcia kultury uczestnictwa i próbuje na nowo przyjrzeć się możliwościom budowania otwartej, dialogicznej kultury nastawionej na twórczą partycypację i współpracę jej uczestników i uczestniczek, w oparciu o powszechnie dostępne nowe technologie. Tekst porusza wątek kompetencji przyszłości, które będą niezbędne do rozwoju kultury i edukacji uczestnictwa oraz aktywnego wykorzystywania nowości w edukacji (i nie tylko).

Słowa kluczowe: kultura uczestnictwa, edukacja uczestnictwa, pedagogika cyfrowa, edukacja cyfrowa, kompetencje przyszłości

\section{Techno-educational trends and the need to develop future competences. Challenges of participatory education}

The article deals with current technological trends in education. It points them out, emphasizing that they function in the context of changes associated with the fourth technological revolution. It draws attention to the importance of reflection on the effects of using new technologies for pedagogy, including special pedagogy. It is also extremely important to design applications of new products and the fact that you cannot think about using them and preparing to use them (and subsequent technologies) without pedagogical reflection. Considering new products through the prism of skills and knowledge, but also of transmitted values. To this end, the author draws on the concept of participatory culture and tries to look again at the possibilities of building an open, dialogical culture focused on the creative participation and cooperation of its participants based on widely available new technologies. The article touches on the topic of future competences, which will be necessary for the development of culture and participatory education as well as for the active use of novelties in education (and more).

Keywords: participatory culture, participatory education, digital pedagogy, digital literacy, future competences 


\section{Gospodarka 4.0, pokolenie alfa i pedagogika}

Kilkanaście lat temu Henry Jenkins z zespołem opublikował dokument Confronting the Challenges of Participatory Culture. Media Education for the 21st Century (Jenkins i in. 2006), podejmujący tematykę wyzwań jakie stoją przed edukacją medialną, która mogłaby przygotowywać do funkcjonowania w świecie przyszłości budowanym na bazie uczestnictwa i zaangażowania jednostek za pomocą mediów. Kultura uczestnictwa - termin promowany przez Jenkinsa (2005) - po latach wydawał się być odbiciem naiwnej wiary w potencjał nowych technologii i jako taki poddany był również refleksji przez polskich badaczy (Stunża i in. 2015; Stachura, Stunża 2016; Bomba, Czarnecki, Stunża 2016). O ile krytyczne podejście wyrażało m.in. niezadowolenie, że pomimo upływu lat nie udało się z wykorzystaniem mediów zbudować kultury otwartej, dostępnej i nastawionej na twórczą aktywność użytkowników, to dzisiaj warto na nowo przemyśleć możliwości budowania takiej kultury. Właśnie na podstawie dostępnych mediów, w odwołaniu do trendów w zakresie korzystania z technologii edukacyjnych i z wykorzystaniem wyników badań dotyczących używania mediów oraz potrzeb w zakresie rozwijania kompetencji przyszłości. Działania w tym zakresie mogą być interesujące również dla pedagogiki specjalnej, jako dyscypliny otwartej na człowieka i budującej kulturę, w której wszyscy traktowani są podmiotowo (ten skrótowy opis ma jedynie zaakcentowanie roli pedagogiki specjalnej w możliwej, ale i już dziejącej się zmianie świata).

Mamy za sobą trzy rewolucje technologiczne, które ukształtowały świat, w jakim funkcjonujemy. Czwarta dzieje się na naszych oczach, a jej umowny początek wyznacza się na dekadę, która niedługo dobiegnie końca (Furmanek 2018). Funkcjonujemy zatem w świecie przełomu technologiczno-gospodarczego, kiedy od gospodarki, w której kluczową rolę odgrywały komputery i dostęp do informacji, przechodzimy do tej, w której technologie chmurowe, automatyzacja, internet rzeczy i wszechrzeczy oraz narzędzia wykorzystujące rzeczywistość wirtualną są szeroko wykorzystywane (Furmanek 2018).

Pierwsze dzieci z tzw. pokolenia Alfa, wyróżnionego tak m.in. z uwagi na rozpoczętą w 2010 r. produkcję iPadów i wczesny dostęp do dotykowych interfejsów, są na progu ukończenia wczesnej edukacji (Pokolenie "Alfa”, 2019). Żyjemy w kulturze przetykanej mediami cyfrowymi, a bariera pomiędzy człowiekiem a technologiami zaciera się. Komputery to obecnie nie tylko urządzenia stacjonarne czy quasi-mobilne laptopy. Funkcjonujemy w rzeczywistości poszerzanej nieustannie przez media mobilne, a symbolem zanurzenia, w szerszym niż otaczający świat, są ekrany. Popularne od ponad stu lat, przez dziesięciolecia gromadziły przed sobą ludzi i były pretekstem do spotkania, teraz rozumiane jako podręczne 
narzędzia komunikowania, pełnią funkcję technologii osobistych, są punktem wstępu do świata informacji, ale również pełnią rolę poszerzenia pamięci, lokalizatora, dostępu do znajomych, ułatwiają pracę i przebywanie z ludźmi pomimo fizycznej odległości.

Tekst ten nie ma na celu przedstawiania technologii i ich potencjału wykorzystania przez ludzi w jak najbardziej pozytywnym świetle. Zwracać będzie raczej uwagę na nowe narzędzia i trendy oraz praktyki medialne, które nie będą bez znaczenia dla funkcjonowania ludzi w niedalekiej przyszłości, ale również stawać się będą coraz bardziej istotne dla pedagogiki i jej subdyscyplin. Także praktyków i praktyczek edukacyjnych, decydentów i osób organizujących działanie formalnego systemu edukacji w Polsce oraz podejmujących działania poza typowymi zadaniami systemu edukacyjnego. W tym kontekście refleksja nad edukacją jutra to przede wszystkim refleksja nad kompetencjami, które będą potrzebne w świecie m.in. niestabilnego zatrudnienia, w którym wiele zawodów zniknie, a tych, które się pojawią, nie da się obecnie precyzyjnie określić. Kompetencje jutra są nierozerwalnie związane z technologiami, które są wykorzystywane na co dzień przez ludzi, ale również z projektowaniem środowisk edukacyjnych z ich wykorzystaniem i promowaniem nowych lub sprawdzonych metod edukacyjnych, być może dostosowanych do nowych wyzwań i narzędzi. I chociaż nie stanowią spójnej, twardej listy wiedzy, umiejętności i postaw niezbędnych w rzeczywistości jutra, przyjrzenie się propozycjom w tej kwestii może być inspiracją do codziennych działań praktycznych, a może również podstawą do modyfikacji całego systemu edukacyjnego.

\section{Trendy edukacyjno-technologiczne}

Trudność w definiowaniu aktualnych trendów związanych z wykorzystaniem technologii w edukacji wynika z różnorodności ośrodków i ekspertów publikujących przewidywania $w$ tym zakresie. O ile można powiedzieć, że jest to aktywność związana z prowadzeniem badań i diagnozowaniem rzeczywistości społeczno-technologicznej, i bez wątpienia edukacyjnej, to raczej nie można określić jej jako działalności związanej tylko lub głównie z ośrodkami akademickimi. Refleksja nad nowościami w tym zakresie pojawia się - oczywiście - wśród badaczy edukacyjnych oraz praktyków wdrażających innowacje, testujących ich potencjał, ale wiąże się mocno z podmiotami o charakterze komercyjnym, które owe innowacje tworzą i propagują. Próbują one odnotowywać pojawianie się pewnych praktyk i wykorzystywanie określonych typów narzędzi oraz metody używane do ich stosowania, w celu lepszego dostosowania się do rynku i oferowania kolejnych produktów. To także analityczne podejście, próbujące przedstawiać 
nowe możliwości podejmowania aktywności edukacyjnych (o rozmaitym charakterze).

Źródeł jest wiele, nie powinno jednak dziwić, że nie są to tylko raporty badawcze. W poszukiwaniach informacji o bieżących trendach na gruncie polskim, trafiłem m.in. do ekspertów edukacyjnych. Przykładem może być Krzysztof Wojewodzic, przed kilkoma laty ekspert Ministerstwa Edukacji Narodowej, odpowiedzialny za wdrażanie e-podręczników, a obecnie przedsiębiorca m.in. w branży IT. Wyróżnił on sześć trendów technologiczno-edukacyjnych, które są i będą istotne w kontekście edukacji wykorzystującej technologie cyfrowe: mobilna edukacja, MOOC (ang. massive open online courses - masowy otwarty kurs online; przyp. gds), nauka programowania i robotyki, analityka edukacyjna, VR (ang. virtual reality - wirtualna rzeczywistość; przyp. gds), uczenie się społecznościowe (Wojewodzic 2018). Zwraca on uwagę na dostępność urządzeń, które podłączone do sieci pozwalają korzystać z jej edukacyjnych zasobów w postaci kursów lub uczenia się z użyciem serwisów społecznościowych, ale także na rozwijającą się edukację związaną z programowaniem ( $w$ tym programowaniem robotów) i możliwość immersji w środowiskach edukacyjnych lub zanurzeniowe korzystanie z materiałów dzięki wirtualnej rzeczywistości. Przedstawione przez eksperta trendy są efektem jego poszukiwań i diagnozy, ale w kilku punktach pokrywają się z innymi propozycjami $\mathrm{w}$ tym zakresie.

Powyższe wątki pojawiają się także w zestawach trendów związanych z wykorzystaniem technologii w edukacji, wskazywanych przez różnorodne podmioty. ELearning Industry wymienia: tablice interaktywne, sztuczną inteligencję, rozszerzoną i wirtualną rzeczywistość, technologię blockchain, analitykę edukacyjną, uczenie się adaptacyjne (eLearning Industry, 2019). Firma Acer - jeden z potentatów branży komputerowej - przez swój dział "Acer for education” wskazywała w 2018 r. osiem trendów edukacji z wykorzystaniem technologii: wirtualną, rozszerzoną i mieszaną rzeczywistość, technologię przeciwko znęcaniu się, technologię chmurową, mobilną edukację, kodowanie i internet rzeczy, technologię i sztukę, wzmacnianie kreatywności oraz edukację dla wszystkich (Acer 2018). Co ciekawe, Acer for Education zwraca uwagę również na specjalne potrzeby edukacyjne i w tym kontekście proponuje personalizację - dobór narzędzi i aplikacji oraz w miarę możliwości dostosowywanie ich do indywidualnych potrzeb, np. korzystanie z technologii zamiany tekstu na mowę, wytłaczarek Braille'a, używanie technologii pozwalających unikać rozpraszania, jak np. blokery reklam czy roboty lub narzędzia pozwalające na teleobecność w szkole (Acer, 2019). Wszystko w zależności od potrzeb osób z niepełnosprawnością i dostępu do odpowiednich technologii.

Trendy związane z korzystaniem z technologii edukacyjnych opisuje także Google for Education. W raporcie poświęconym przyszłości klasy szkolnej podaje 
osiem rozwijających się trendów: odpowiedzialność cyfrową, myślenie komputacyjne, współpracę klasową, pedagogikę innowacji, umiejętności życiowe i przygotowanie do pracy, edukację liderów edukacyjnych, lączenie opiekunów i szkół, nowo powstające technologie (Future of the Classroom, 2019).

Jak widać, niektóre z pozycji wymienianych przez różne podmioty i ekspertów, powtarzają się i łączą z elementami wskazanymi wcześniej jako wątki opisujące gospodarkę 4.0. Jest tak np. w przypadku wirtualnej i rozszerzonej rzeczywistości, analityki edukacyjnej, uczenia się z wykorzystaniem technologii współpracy, korzystaniem z sieciowych zasobów i szkoleń, edukację w zakresie rozumienia $\mathrm{i}$ korzystania $\mathrm{z}$ technologii, $\mathrm{w}$ tym kodowania i obsługi robotów. Trendy przedstawione wyżej stanowią co prawda wybór propozycji, ale widać wyraźnie, że łączą one korzystanie z określonych technologii z promocją pewnych wartości, jak np. krytyczny odbiór, przygotowanie do życia (w tym osób z niepełnosprawnościa$\mathrm{mi})$, stawianie na wspólpracę, innowacje i dzielenie zasobów. Wyzwania związane $\mathrm{z}$ trendami w zakresie technologii edukacyjnych wykraczają zatem daleko poza wąskie przygotowanie do używania technologii, ale prezentują również kontekst społeczny i konieczność namysłu nad skutkami korzystania z technologii, zasadami związanymi z ich używaniem itp.

Trendy dostrzegane przez ekspertów i twórców technologii (oraz kreowane przez nich) korespondują z wynikami badań. Przykładem może być rosnąca popularność np. telewizji na żądanie i częstsze korzystanie z niej w amerykańskich rodzinach z małymi dziećmi niż z telewizji kablowej (The Common Sense Census, 2017). Warto także zwrócić uwagę na coraz szerszy dostęp do wirtualnej rzeczywistości - gogle do VR czy rozszerzonej - rosnąca popularność asystentów głosowych opartych na sztucznej inteligencji i tworzone na tej podstawie produkty, przykładem są choćby efekty współpracy Amazonu z Lego Duplo (Ong 2018). Co ciekawe, powszechny dostęp do technologii nie przekłada się bezpośrednio na twórcze wykorzystywanie i aktywne zaangażowanie w różnorodne działania. Młodzi publikują niemal codziennie zdjęcia i filmy - 78\% (Tanaś i in. 2016), ale tylko 10\% dzieci i nastolatków w wieku 9-17 lat stworzyło i opublikowało plik wideo lub audio w sieci (Pyżalski 2018).

\section{Technologie przyszłości i kompetencje jutra.} Kompetencje przyszłości i trendy edukacyjne

Podejmując temat kompetencji przyszłości sięgnąłem do wniosków polskich badaczek. Digital Economy Lab Uniwersytetu Warszawskiego przedstawił raport, prezentujący obszary kompetencji, które już dzisiaj są istotne z perspektywy 
przygotowywania do przemian związanych z rozwojem technologii i bez skupienia się na nich możemy nie mieć możliwości odpowiedniego wykorzystania potencjału ludzkiego i technologicznego. Co prawda, badanie nie było prowadzone na reprezentatywnej próbie i wzięli w nim udział uczestnicy i uczestniczki pierwszej edycji warsztatów poświęconych design thinking (warsztaty organizował Google we współpracy z Polskim Funduszem Rozwoju). Warto wziąć pod uwagę, że uczestniczyli w nich studenci i absolwenci aktywni, poszukujący wiedzy i chętni rozwijać swoje umiejętności. Analiza ich wypowiedzi i zwrócenie uwagi na wskazane przez nich braki związane z kształceniem uniwersyteckim warto potraktować zatem jako istotny głos. Głównym wątkiem $w$ raporcie jest zmiana związana z rozwojem technologii, czwartą rewolucją technologiczną oraz rolą uniwersytetów $\mathrm{w}$ tym procesie. Uczestnicy mówili o tym, czego podczas studiów im zabrakło, do czego nie zostali przygotowani i jakie są ich potrzeby związane z niepewną przyszłością wielu zawodów. W raporcie można przeczytać o prognozowanych zmianach $w$ funkcjonowaniu wielu profesji. Wskazane zostały zawody nowe, zawody, które będą miały stabilną pozycję oraz te, które prawdopodobnie będą zbędne. Poza badaniami z uczestni(cz)kami warsztatów przywołane zostały raporty różnych podmiotów zajmujących się rynkiem pracy (Włoch, Śledziewska 2019).

Autorki raportu wskazały trzy obszary kompetencji przyszłości, których rozwój jest kluczowy: kompetencje poznawcze, kompetencje społeczne i kompetencje techniczne. Dokument jasno wskazuje, że kompetencje cyfrowe rozwijane są autorki stosują uczelnianą skalę ocen - dostatecznie; społeczne i emocjonalne dostatecznie z minusem; kompetencje poznawcze - dobrze, ale z zaznaczeniem, że mogłoby być lepiej. O zawartości mówi już wyraźnie spis treści. W części poświęconej wyzwaniom znalazły się punkty „Za dużo wykładów, za mało warsztatów”, ,Brak tolerancji dla błędów i eksperymentowania” czy „Pasjonat poszukiwany". Tytuły te mówią dużo, a ich rozwinięcie jeszcze więcej o kondycji systemu szkolnictwa wyższego. W raporcie znajdują się również przykłady dobrych praktyk oraz rekomendacje, przedstawiona jest także, w postaci krótko omówionych haseł, wizja uniwersytetu przyszłości (Włoch, Śledziewska 2019). I chociaż wydawać by się mogło, że tylko obszar kompetencji technicznych jest związany z wykorzystaniem technologii, to jednak szczegółowe, wybrane aspekty kompetencji społecznych, jak współpraca z innymi, zarządzanie ludźmi, odbywają się obecnie i będą także w przyszłości, z użyciem cyfrowych technologii; podobnie kompetencje poznawcze: krytyczne myślenie związane choćby z odbiorem informacji $\mathrm{w}$ środowisku cyfrowym, kreatywność połączona z wykorzystywaniem cyfrowych narzędzi twórczych czy rozwiązywanie złożonych problemów np. z wykorzystaniem narzędzi do analizowania danych różnego typu. 


\section{Edukacja do odkrywania świata}

Jak rozwijać kompetencje przyszłości? Być może jedną z opcji byłoby przywrócenie uczniom i studentkom statusu odkrywców. Jako nauczyciele i wykładowcy skupiliśmy się mocno, co akcentuje wspomniany raport DELab UW, na odtwarzaniu zamiast tworzenia, na odwoływaniu do znanego, zamiast odkrywania nieznanego. Zgasiliśmy w pewnym sensie ciekawość i ducha dziecięcej eksploracji, a dzisiaj nawet przedszkola - do niedawna ostoja swobody edukacyjnej - zamieniają się $\mathrm{w}$ miejsca przypominające klasy szkolne. $\mathrm{W}$ tym miejscu warto powołać się na profesora Mitcha Resnicka, dyrektora Lifelong Kindergarten w Medialabie Massachussets Institute of Technology, który mówi o konieczności czerpania w edukacji z wzorca, jakim jest przedszkole (Resnick 2018). Bazując na pomyśle Resnicka, który jest jednym z twórców języka programowania Scratch, przygotowanego z myślą o edukacji programistycznej dzieci, moglibyśmy postawić na badanie świata przez dzieci, na podtrzymywanie ducha odkrywania, tworzenia, generowania rozwiązań problemów, które również należy swobodnie stawiać. Przedszkole powinno być symbolem radości ze zdobywania wiedzy, nieustannego rozwoju i dziecięcego pytania "dlaczego"?

Podstawowy, dominujący obecnie trend edukacyjny, to de facto nie innowacje technologiczne i sposoby ich wykorzystywania, ale niemal powszechna zgoda na odhumanizowaną edukację $\mathrm{w}$ połączeniu $\mathrm{z}$ wiarą $\mathrm{w}$ magiczną moc technofetyszyzmu i postępu edukacyjnego, bazującego głównie na kupowaniu, nie zawsze odpowiednio przemyślanym, nowych narzędzi edukacyjnych. Szkoły $\mathrm{w}$ większości nie pozwalają na korzystanie z urządzeń mobilnych uczniów, podczas gdy BYOD (Bring Your Own Device - przynieś swój własny sprzęt) jest używany przez wielu innowatorów i posiada sporo przykładów działań (Głomb 2018). Zgodziliśmy się, żeby szkoła była od odkopywania nieistotnych informacji, zamiast tworzenia wiedzy. Można się obawiać, że szkoła w dzisiejszej formule będzie działać na niekorzyść rozwoju kompetencji potrzebnych w przyszłości. Przyszli nauczyciele nie uczą się współpracy, a mają jej uczyć (wystarczy zajrzeć do programów studiów przyszłych nauczycieli, pomijając programy pedagogiki). Nie korzystają z nowych narzędzi, a mają rozwijać kreatywność i umiejętność poradzenia sobie w szybko zmieniającym się świecie, nie uczą podejmowania decyzji, dyskutowania i asertywności.

Jak pokazuje projekt „Will Robots Take My Job” (https://willrobotstakemyjob. com/), to co automatyczne lub co będzie można zautomatyzować (a sztuczna inteligencja sprawi, że będą to również pewne działania twórcze), będzie zautomatyzowane. To, co zostanie dla ludzi, będzie miało ludzki wymiar, oparty na emocjach, współpracy, abstrakcyjnym myśleniu, wymianie poglądów. Co ciekawe, 
dzisiejsza szkoła korzysta z technologii i znajdą się w niej z czasem rozwiązania $\mathrm{w}$ tej chwili uważane za nowe, ale będą prawdopodobnie niepotrzebne lub źle zorganizowane i wykorzystywane - przykładem niech będzie tablica interaktywna, która nie wniosła do szkoły wyraźnej zmiany, a przez niektóre źródła wskazywana jest wciąż jako innowacja edukacyjna (eLearning Industry, 2019).

\section{Technologie człowieczeństwa? Jak twórczo budować kulturę uczestnictwa?}

Myśląc o używaniu cyfrowych narzędzi w edukacji warto najpierw skupić się na rozwoju "technologii człowieczeństwa”, a może po prostu kompetencji potrzebnych nam jako ludziom, właściwie bez względu na postęp technologiczny (ale pamiętając o nim). Dlatego istotne jest zwrócenie uwagi nie tylko na kompetencje cyfrowe w rozumieniu technicznym, ale także na wskazane przez autorki raportu kompetencje społeczne i poznawcze (Włoch, Śledziewska 2019), które są niezbędne do funkcjonowania $\mathrm{w}$ świecie, $\mathrm{w}$ którym przetwarzanie informacji jest niezbędne do aktywnego działania. Żyjemy w nieustannym kryzysie - już od niemal trzydziestu lat refleksja i dyskusja nad korzystaniem z sieci jest zdominowana przez dyskurs nieustannego wahania, który określić można hasłem „„szansa czy zagrożenie?". Żeby zmienić sytuację, nie wystarczy zapoznanie z aplikacjami do tworzenia. Potrzeba rozbudzenia ochoty na twórczość, wykraczającą poza kontekst rówieśniczej komunikacji za pomocą aplikacji, jak np. Instagram.

Dopełnieniem kompetencji przyszłości opisanych $w$ raporcie DELAB UW może być kilka kwestii, które są, moim zdaniem, istotne dla rozwoju kompetencji przyszłości, a także wpisują się w postulaty budowania kultury uczestnictwa, od której zacząłem niniejszy tekst. Byłyby to: otwartość, eksploracja, współpraca i dialog, diagnozowanie/badanie otoczenia, doskonalenie warsztatu pracy, rozwiązywanie problemów, podejmowanie decyzji, podział obowiązków, wyszukiwanie i (krytyczna) ocena informacji, samodoskonalenie, rozumienie działania technologii i podstawy programowania. Podstawą zmiany mogłaby być modyfikacja systemu kształcenia nauczycieli. Pokazanie dobrych przykładów, zwrócenie uwagi, że edukacja to dialog pomiędzy jednostkami. Model hierarchicznej komunikacji nie jest niezbędny, a bywa, że szkodliwy w procesie edukacyjnym. Skupienie się na rozwijaniu ludzkich cech: empatii, otwartości na innych, otwartości na nowości, eksploracji otoczenia, a także rozwijaniu umiejętności badania otaczającego świata $\mathrm{w}$ połączeniu $\mathrm{z}$ wdrażaniem wniosków i refleksji na ich temat, są konieczne. Konieczne jest także poczucie bezpieczeństwa w instytucji edukacyjnej. Nie powinniśmy się bać, potrzebujemy przestrzeni, która jest nasza, 
w której się dobrze czujemy, w której chcemy przebywać i działać. To wymaga wspólpracy grup zaangażowanych w edukację: w szkole - rodziców, uczniów, uczennic, nauczycieli i nauczycielek; w uniwersytecie - studentek, studentów oraz wykładowców i wykładowczynie, a także partnerstw z instytucjami, organizacjami i podmiotami biznesowymi.

Potrzeba również swobody odkrywania. Testowanie ról, budowanie prototypów, nawet jeśli nie prowadzą do konkretnego efektu, są bardzo istotne. Ważna jest także współpraca z innymi, ale by jej uczyć, trzeba samemu współpracować, a to umiejętność, której szkoła wciąż nie potrafi rozwijać, a uniwersytety często pogłębiają lukę lub nie próbują akcentować umiejętności współpracy. Podstawą edukacji nie powinny być również technologie, ale wymiana informacji, myślenie, szacunek dla drugiej osoby, wspólne określanie celów. Techno-fetyszyzm nie jest dobrym pomysłem, co na przykładzie dobrze wyposażonych uczelni niemieckich omówiły autorki raportu (Włoch, Śledziewska 2019). Tam, gdzie nie ma kreatywności i chęci komunikacji, współtworzenia, gdzie nie ma kultury przetwarzania i krytycznego odbioru informacji, nie pomogą żadne nowe narzędzia dydaktyczne.

To co ogromnie istotne, to nieustanna zmienność technologiczna, do której musimy być przyzwyczajeni, ale i na nią gotowi. I to w sytuacji, kiedy szkoła nie zmienia się zbyt szybko, a paradoksalnie czasami robi to zbyt szybko, co należy czytać - bezrefleksyjnie. A to z kolei może rodzić szereg problemów utrudniających rozwijanie kompetencji (do) przyszłości. Myśląc o prowadzeniu edukacji z wykorzystaniem mediów, przygotowywaniu do ich aktywnego używania oraz próbując dzięki temu budować kulturę uczestnictwa przez działania z zakresu edukacji uczestnictwa (Stunża 2018), warto pamiętać, że dzieci już od najmłodszych lat uczą się używania mediów, obserwując otoczenie, naśladując najbliższych, a kluczem do sukcesu $w$ tej materii jest także motywacja nauczycieli i rodziców, a nie posiadany sprzęt (Chaudron, Di Gioia, Gemo 2018).

\section{Bibliografia}

Education Technology Trends for 2018 (2018), Acer for Education, https://eu-acerforeducation. acer.com/education-trends/8-education-technology-trends-for-2018/ [dostęp: 10.12.2019].

Bomba R., Czarnecki S., Stunża G.D. (2016), Tylko dostęp? Koniec kultury uczestnictwa, Kultura Współczesna, 1(89).

Chaudron S., Di Gioia R., Gemo M. (2018), Young Children (0-8) and Digital Technology. A qualitative study across Europe, European Comission.

Furmanek W. (2018), Najważniejsze idee czwartej rewolucji przemysłowej (industrie 4.0), Dydaktyka Informatyki, 13. 
Future of the Classroom. Emerging Trends in K-12 Education Global Edition (2019), Google for Education, http://services.google.com/fh/files/misc/future_of_the_classroom_emerging_trends_in_k12_education.pdf [dostęp: 18.12.2019].

Głomb K. (red.) (2018), Smartfon jako osobiste narzędzie edukacyjne ucznia, Kometa Sieć Edukacji Cyfrowej.

Jarman B. (2019), 2019 EdTech Trends You Should Be Excited About. eLearning Industry, https://elearningindustry.com/2019-edtech-trends-excited [dostęp: 12.12.2019].

Jenkins H., Clinton K., Purushotma R., Robison A., Weigel M. (2006), Confronting the Challenges of Participatory Culture. Media Education for the 21st Century, MacArthur Foundation.

Jenkins H. (2005), Kultura konwergencji. Zderzenie starych i nowych mediów, Wydawnictwa Akademickie i Profesjonalne.

Ong T. (2018), Lego's new Alexa skill has voice-guided instructions and tells stories. "The Verge" 03.05.2018, https://www.theverge.com/2018/5/3/17314100/lego-duplo-stories-interactiveskill-amazon-alexa [dostęp: 15.12.2019].

Pokolenie "Alfa”. Raport (2019), Leader Sheep, Łódź.

Pyżalski J., Zdrodowska A., Tomczyk Ł., Abramczuk K. (2018), Polskie badanie EU Kids Online 2018. Najważniejsze wyniki i wnioski, Wydawnictwo Naukowe UAM, Poznań.

Resnick M. (2018), Lifelong Kindergarten: Cultivating Creativity through Projects, Passion, Peers, and Play, The MIT Press.

Stunża G.D. (2018), Wyzwania kultury i edukacji uczestnictwa. Pokolenie Z i pokolenie Alfa, Edukator Medialny, Gdańsk.

Stunża G.D., Bomba R., Siuda P., Stachura K. (2015), Dwa zero czy zero? Blogi o tematyce kulturalnej a przemiany kultury uczestnictwa, Instytut Kultury Miejskiej, Gdańsk.

Stachura K., Stunża G.D. (2016), Wstęp. Kultura i edukacja od nowa. Bez granic między rozważaniem a działaniem [w] K. Stachura, G.D. Stunża (red.), Kultura od nowa. Badania - trendy praktyka", Instytut Kultury Miejskiej, Gdańsk:.

Tanaś M. i in. (2016), Nastolatki 3.0. Wybrane wyniki ogólnopolskiego badania uczniów w szkołach, NASK.

The Common Sense Census: Media Use by Kids Age Zero to Eight (2017), Common Sense.

The key role of EdTech in Special Education (2019), Acer for Education, https://eu-acerforeducation.acer.com/education-trends/the-key-role-of-edtech-in-special-education/ [dostęp: 17.12.2019].

Will Robots Take My Job, https://willrobotstakemyjob.com/ (dostęp: 12.12.2019).

Włoch R., Śledziewska K. (2019), Kompetencje przyszłości. Jak je kształtować w elastycznym ekosystemie edukacyjnym, DELab UW, Warszawa.

Wojewodzic K. (2018), Trendy w edukacji i edtech 2018-2020, 3. Forum Aplikacji i Gier Mobilnych, https://youtu.be/YbEhywB8nZY [dostęp: 14.12.2019].

Wojewodzic K. (2018), 6 trendów EdTech, które mają znaczenie, https://gomobi.pl/blogi/6-trendow-edtech-ktore-maja-znaczenie/ [dostęp: 15.12.2019]. 